\title{
Computed tomography of the chest in patients with COVID-19: what do radiologists want to know?
}

\author{
Ahmed Razek ${ }^{A, B, D, E, F}$, Nehad Fouda ${ }^{B, C, D}$, Dalia Fahmy ${ }^{B, F}$, Mohamed Salah Tanatawy ${ }^{D, E}$, Amina Sultan ${ }^{B}$, \\ Maha Bilal ${ }^{D, E}$, Maysaa Zaki ${ }^{D, E}$, Mahmoud Abdel-Aziz ${ }^{D, E}$, Donia Sobh ${ }^{D, E}$ \\ Faculty of Medicine, Mansoura University, Mansoura, Egypt
}

\begin{abstract}
We aim in the current study to review pulmonary and extra-pulmonary imaging features in patients infected with COVID-19. COVID-19 appears to be a highly contagious viral disease that attacks the respiratory system causing pneumonia. Since the beginning of the outbreak, several reports have been published describing various radiological patterns related to COVID-19. Radiological features of COVID-19 are classified into; pulmonary signs of which ground glass opacities are considered the characteristic followed by consolidation, and extra-pulmonary signs such as pulmonary embolism and pneumothorax, which are far less common and appear later in progressive disease. We review the different structured reporting systems that are published by different groups of radiologists using simple unified terms to enable good communication between the radiologist and the referring physician. Computed tomography of the chest is beneficial for early diagnosis of COVID-19 pneumonia, assessment of disease progression and guide to therapy, surveillance of patients with response to therapy, prediction of overlying bacterial infection, differentiation from simulating lesions, and screening with prevention and controls of the disease.
\end{abstract}

Key words: computed tomography, COVID-19, respiratory, pneumonia.

\section{Introduction}

Coronavirus disease 2019 (COVID-19) is a novel new type coronavirus of zoonotic origin with human-tohuman transmission that was officially named by the World Health Organisation (WHO). The first reported cases were in Wuhan, Hubei province, China, which then disseminated all over China and later to other countries across the world that fear to have the potential to cause a pandemic. This infection originated in a wet "seafood market" in Wuhan, and it has a mean incubation period of 5.2 days. These patients suffer from severe pneumonia, in the form of fever, fatigue, dry cough, and respiratory distress [1-10]. Chest computed tomography (CT) and plain $\mathrm{X}$-ray play a crucial role in the detection of early pulmo- nary changes and surveillance of patients with COVID-19. Several recent studies discuss the role of chest CT and $\mathrm{X}$-ray in COVID-19 infection [11-33].

The aim of this study is to review the basic background and chest CT imaging findings in patients with COVID-19 infection.

\section{Epidemiology}

Coronaviruses are non-segmented, enveloped, singlestrand viruses, with four mild species present with mild respiratory symptoms, and three severe forms called severe acute respiratory syndrome (SARS), Middle East respiratory syndrome (MERS), and the more recently identified coronavirus disease 2019 (COVID-19), which cause epidemics with high mortality rates. Different varieties of

Correspondence address:

Ahmed Razek, MD, Mansoura University Hospital, Egypt, e-mail: arazek@mans.edu.eg

Authors' contribution:

A Study design · B Data collection · C Statistical analysis · D Data interpretation · E Manuscript preparation · F Literature search · G Funds collection 
Coronaviruses are seen in bats, which are considered reservoirs for several viruses [1-5]. COVID-19 is assumed to be primarily hosted by bats, and then transmitted to humans through pangolin or other wild animals sold at the Wuhan seafood market with subsequent transmission from humans to humans. The incubation period infected with COVID-19 ranged from 3 to 7 days and up to 14 days. $\mathrm{Pa}-$ tients can become the source of infection in the incubation period; therefore, early detection of infected patients is beneficial to control the spread of infection. The fatality rate is about $2.3 \%$. The average number of new infections from an infected patient to a naive population is 3.28 , indicating that this disease will spread according to WHO rules [4-9].

\section{Clinical presentation}

The clinical presentation of patients with COVID-19 is non-specific including fever (98\%), cough (75\%), and myalgia or fatigue (45\%), dyspnoea (55\%), and acute respiratory distress syndrome (20\%) and may progress to multiorgan dysfunction (e.g., shock, acute respiratory distress, acute cardiac dysfunction, acute kidney dysfunction) and even death (2.5\%) [4-10].

\section{Laboratory}

The real-time reverse transcription-polymerase chain reaction (RT-PCR) assay is considered now as the gold-standard for diagnosis of COVID-19. However, this test may be associated with false-negative results from sampling errors and low-virus overload, not widely available, expensive, takes a long time for analysis and must be check by skilled personnel, while antibody-based techniques are used as supplemental tools [2-7].

\section{Computed tomography findings}

Imaging findings of COVID-19 at CT can be classified into pulmonary findings (Table 1) and extra-pulmonary findings (Table 2).

\section{Pulmonary findings \\ Ground glass opacity}

Ground glass opacity (GGO) is described as hazy areas with slightly increased density in the lungs, but with un-

Table 1. Pulmonary findings in COVID-19

\begin{tabular}{|c|c|}
\hline Pattern & Description \\
\hline GG0 appearance & $\begin{array}{l}\text { Hazy areas with slightly increased density in lungs without obscuration of bronchial and vascular margins } \\
\text { Bilateral, multifocal, peripheral, lower zone predominance } \\
\text { Most common sign in CT }\end{array}$ \\
\hline Consolidation & $\begin{array}{l}\text { Homogenous opacification that obscures blood vessels and airway walls } \\
\text { Bilateral multifocal and subsegmental } \\
\text { Peripheral more than bronchocentric } \\
\text { Could develop in centre of } \mathrm{GGO} \\
\text { Most common sign in X-ray } \\
\text { Sign of disease progress }\end{array}$ \\
\hline Mixed consolidation and GG0 & GG0 accompanied by small areas of consolidation \\
\hline Crazy paving & $\begin{array}{l}\text { GGO with superimposed inter and intra-lobular septal thickening, resembling stone paving } \\
\text { Sign of disease progress }\end{array}$ \\
\hline Halo sign & GGO surrounding a pulmonary nodule \\
\hline Reversed halo sign & $\begin{array}{l}\text { Round area of } \mathrm{GGO} \text { surrounded by a complete or almost complete ring (more than } 3 / 4 \text { of a circle) of } \\
\text { consolidation, at least } 2 \mathrm{~mm} \text { in thickness } \\
\text { Mostly lower lobe, peripheral in location, smooth peripheral rim } \\
\text { Moderate disease }\end{array}$ \\
\hline Air bubble sign & A small air-containing space in the lung \\
\hline Centrilobular nodules & $\begin{array}{l}\text { A nodule is a rounded opacity, well or poorly defined, measuring up to } 3 \mathrm{~cm} \text { in diameter, in centrilobular } \\
\text { distribution } \\
\text { Rare sign, more with other viral diseases }\end{array}$ \\
\hline Subpleural curvilinear opacity & $\begin{array}{l}\text { Subpleural curvilinear lines are 1-3 } \mathrm{mm} \text { in thickness, lying less than } 1 \mathrm{~cm} \text { from and parallel to the pleural } \\
\text { surface }\end{array}$ \\
\hline Reticular pattern & $\begin{array}{l}\text { Thickening of the interstitial structures like inter and intra-lobular septations (stripe like opacities) } \\
\text { Sign of disease progress }\end{array}$ \\
\hline Fibrosis & $\begin{array}{l}\text { Linear dense peripheral opacities, parenchymal bands and irregular interfaces } \\
\text { Sign of disease progress }\end{array}$ \\
\hline
\end{tabular}

GG0 - ground glass opacity, CT - computed tomography 
Table 2. Extra-pulmonary findings in COVID-19

\begin{tabular}{|c|c|}
\hline Pattern & Description \\
\hline \multicolumn{2}{|l|}{ Bronchial tree } \\
\hline Bronchiectasis & $\begin{array}{l}\text { Bronchial dilatation with respect to the accompanying pulmonary artery (signet ring sign), lack of tapering of bronchi, } \\
\text { and identification of bronchi within } 1 \mathrm{~cm} \text { of the pleural surface } \\
\text { Bronchial deformity denotes irreversible damage } \\
\text { Sign of disease progress }\end{array}$ \\
\hline Air bronchogram & Air-filled (low attenuation) bronchi on a background of opaque (high attenuation) airless lung can be seen within GG0 \\
\hline \multicolumn{2}{|l|}{ Vascular } \\
\hline Vascular enlargement & Dilatation of pulmonary vessels around and within the lesions \\
\hline Pulmonary embolism & Hypodense filling defect in pulmonary artery or its branches \\
\hline \multicolumn{2}{|l|}{ Mediastinal } \\
\hline Lymphadenopathy & $\begin{array}{l}\text { Enlarged mediastinal lymph nodes with short axis }>10 \mathrm{~mm} \\
\text { Denotes progressive disease or secondary bacterial infection }\end{array}$ \\
\hline Mediastinal emphysema & Air within mediastinum either due to repeated severe cough or complication of mechanical ventilation \\
\hline \multicolumn{2}{|l|}{ Pleural } \\
\hline Thickening & $\begin{array}{l}\text { Smooth thickening due to scarring } \\
\text { Sign of progressive disease }\end{array}$ \\
\hline Effusion & $\begin{array}{l}\text { Fluid in pleural space } \\
\text { Denotes progressive disease or secondary bacterial infection }\end{array}$ \\
\hline Pneumothorax & $\begin{array}{l}\text { Air in the pleural space with collapse of related lung } \\
\text { Major complication of disease treatment of extensive alveolar damage }\end{array}$ \\
\hline \multicolumn{2}{|l|}{ Cardiac } \\
\hline Pericardial effusion & $\begin{array}{l}\text { Fluid in pericardial space }>7 \mathrm{~mm} \text { in thickness } \\
\text { Rare sign, seen in progressive disease }\end{array}$ \\
\hline \multicolumn{2}{|l|}{ Chest wall } \\
\hline Surgical emphysema & Air within soft tissue of the chest wall either due to repeated severe cough or complication of mechanical ventilation \\
\hline
\end{tabular}

obscured bronchial and vascular margins. This is attributed to the partial filling of alveoli by exudate and alveolar septal inflammation. GGO is the most widely reported radiological sign linked to COVID-19. It is considered one of the earliest signs to appear in CT in the pre-clinical group (asymptomatic) and extends to predominate in the second and third weeks as well. GGO in COVID-19 has a characteristic distribution being peripheral (subpleural), often bilateral, multifocal, possibly nodular or mass-like, and predominantly affecting lower lung lobes. The last feature could be explained by the fact that diseased patients are likely to move less and prefer to lie down, so they develop radiological changes in the most dependent areas of the lungs. Extensive bilateral diffuse GGO (also named bilateral white lungs) is noted in severe cases that may require admission to the intensive care unit (ICU) and intubation [11-16] (Figure 1).

\section{Consolidation}

Consolidation is defined as a homogenous high density that obscures airway walls and blood vessels. In this condition, alveolar air is replaced by other materials (e.g. pathological fluids, cells, or tissues) with subsequent in- crease in pulmonary parenchymal density. It has bilateral, multifocal, and subsegmental distribution. The presence of consolidation is considered a sign of progressive COVID-19 disease, as it develops in the second week after the onset of symptoms. It is seen more in patients over 50 years old, so consolidation could serve as a clue of an illness that necessitates greater vigilance in management [13-19] (Figure 2).

\section{Mixed ground glass opacity and consolidation}

GGO is accompanied by focal, round, small areas of consolidation, which may suggest organising pneumonia. It is a sign of the progress of viral infection. It is found in about 2/3 of cases of COVID-19 [11-15] (Figure 3).

\section{Crazy paving}

Crazy paving is defined as ground-glass opacity superimposed by inter - and intra-lobular septal thickening, resembling stone paving. Like SARS, this pattern may be caused by two events occurring in the same time, alveolar oedema (causing GGO) and interstitial inflammatory reaction (causing septal thickening); both are caused by 

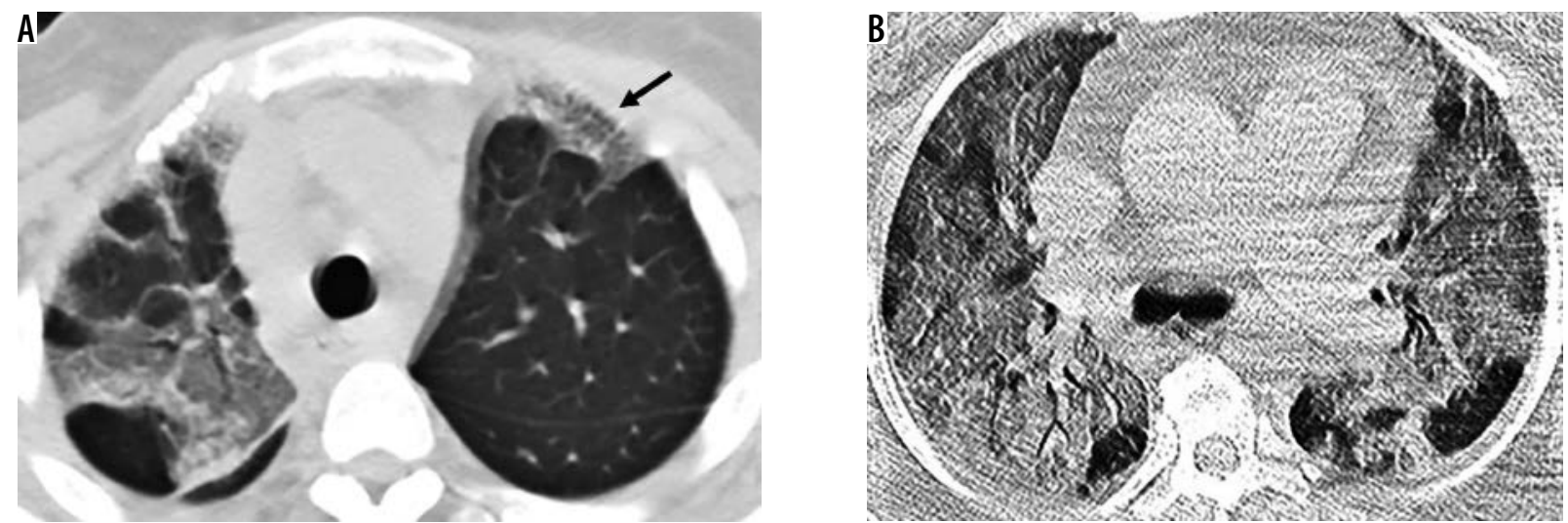

Figure 1. Ground glass opacity (GG0). A) High-resolution computer tomography (HRCT) shows GG0 with air bronchogram at the posterior segment of the right upper lung lobe with thickening of the oblique fissure. There is inter- and intralobular septal thickening overlying the GG0 at the anterior segment of the left upper lung lobe crazy paving (black arrow). B) HRCT shows bilateral diffuse extensive GGO (white lung sign) with air bronchogram and small consolidation at the posterior basal segment of the left lower lung lobe

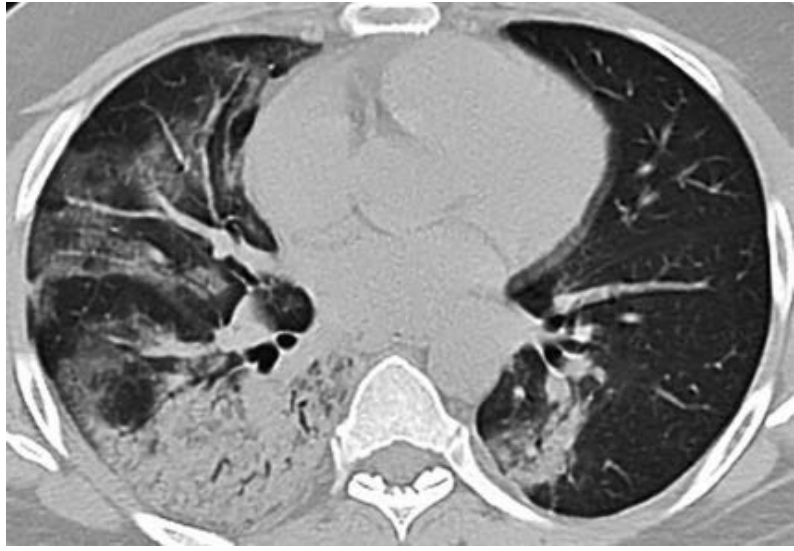

Figure 2. Consolidation. High-resolution computer tomography shows consolidation of the apical segment of both lower lung lobes (more evident on the right side) with air bronchogram; it is associated with multiple peripheral ground glass opacity at the right middle lung lobe

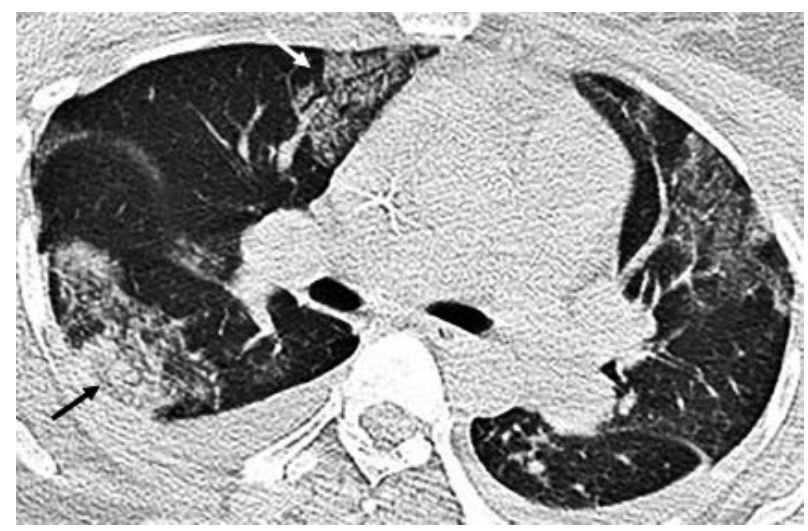

Figure 4. Crazy-paving sign. High-resolution computer tomography shows bilateral multifocal ground glass opacity (GGO) located at medial segment of the right middle lung lobe, apical segment of the right middle lung lobe and superior lingula superimposed by thickened inter and intralobular septations (crazy paving) (white arrow). It is associated with peripheral consolidation (black arrow) developed within GGO and bilateral pleural effusion

acute lung injury. The presence of crazy paving in combination with GGO and consolidation is considered another sign of progression of COVID-19 infection. There is large

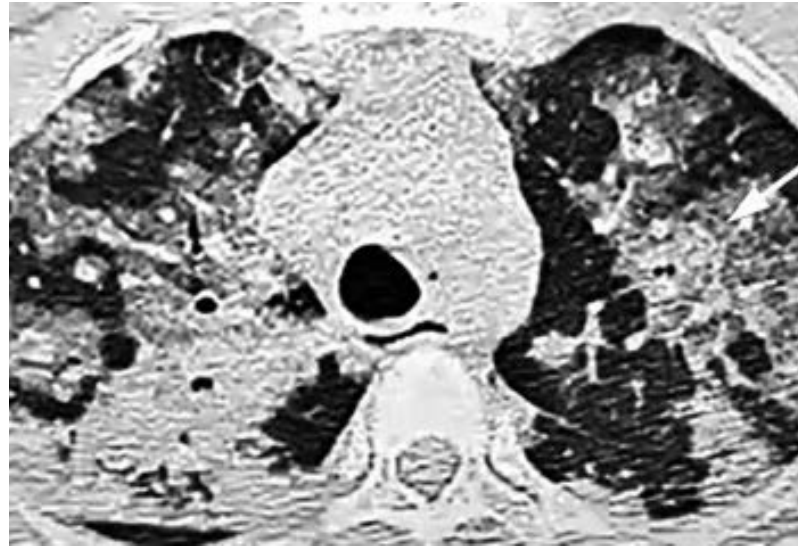

Figure 3. Mixed ground glass opacity (GG0) and consolidation. Highresolution computer tomography shows bilateral multiple multifocal peripheral and bronchocentric consolidations mixed with $\mathrm{GGO}$, together with thick septations giving crazy paving appearance. Note small consolidation developing within $\mathrm{GGO}$ (white arrow)

variability in the prevalence of this sign, ranging from 35 to $90 \%$ [18-25] (Figure 4).

\section{Halo sign}

Halo sign is defined as ground-glass opacity around a pulmonary nodule. This pattern was noted for the first time in immune-compromised patients with invasive pulmonary aspergillosis. The peripheral halo of groundglass opacity is linked to the presence of haemorrhagic nodules, and the mechanism of the haemorrhage may include haemorrhagic infarction, vasculitis, the fragility of the neovascular tissue, broncho-arterial fistula, or necrosis. Hence, the central dense zone corresponds to the nodule, while the surrounding halo of ground-glass opacity corresponds to haemorrhage/haemorrhagic infarction. This sign is seen in several infectious diseases such as varicella-zoster, cytomegalovirus, herpes simplex, and myxovirus. This sign is also described in COVID-19 infection; one recent study found it in $64 \%$ of their cases [18-26] (Figure 5). 


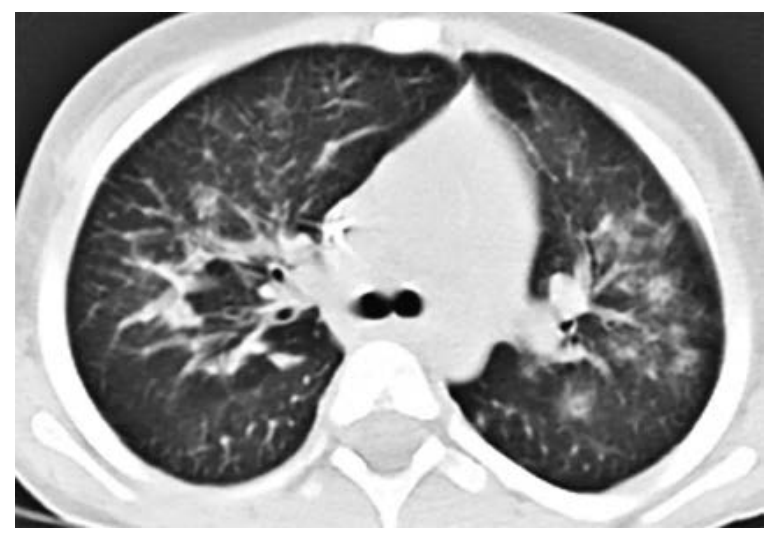

Figure 5. Halo sign. High-resolution computer tomography shows multiple bilateral nodules surrounded by ground-glass opacities (halo sign)

\section{Reversed halo sign}

Reversed halo sign (atoll sign) is defined as a rounded area of ground-glass opacity surrounded by a complete or almost complete dense ring (more than $3 / 4$ of a circle) of consolidation, at least $2 \mathrm{~mm}$ in thickness. The central low-density area (GGO) represents alveolar space opacification by alveolar septal inflammation and cellular debris, while the dense crescent is formed by granulomatous tissue within the distal air spaces. Reversed halo sign was originally described in cryptogenic organizing pneumonia but can also be secondary to other causes. It is infrequently reported in COVID-19 patients, and it is more commonly described in moderate disease than in severe disease. Most lesions are peripheral, located in lower lobes, while their rim is more often smooth than irregular. On follow-up these lesions are resolved in the majority of cases into GGO and linear fibrotic bands [23-29] (Figure 6).

\section{Centrilobular nodules and tree in bud pattern}

Pulmonary nodule is defined as a rounded opacity that might be well or poorly defined and can be up to $3 \mathrm{~cm}$

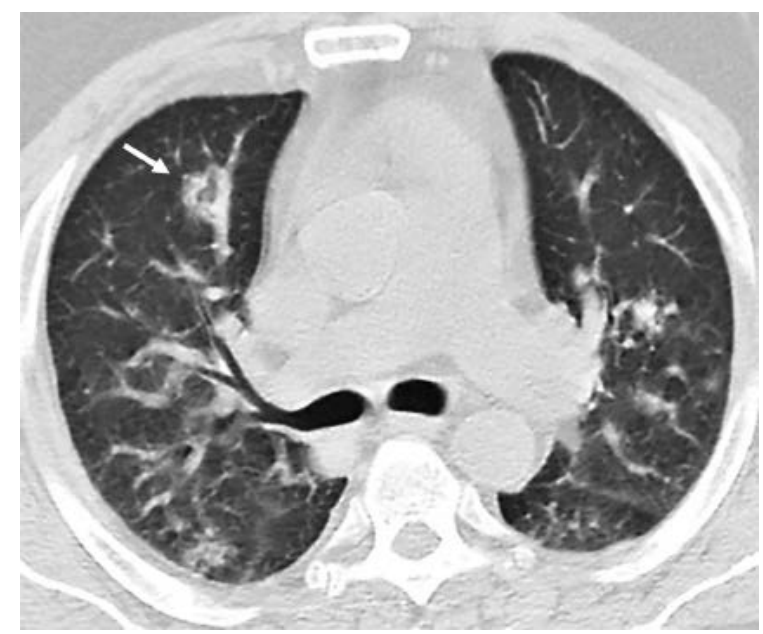

Figure 6. Reversed halo sign. High-resolution computer tomography shows bilateral small ground glass opacity surrounded by a complete dense ring of consolidation giving reversed halo sign (white arrow) in diameter. Pulmonary nodules are classified according to distribution into centrilobular, peri-bronchovascular, and random. The presence of centrilobular nodules is a rare radiological sign in COVID-19. It is considered one of the unlikely signs in several score systems [27-30] (Figure 7).

\section{Air bronchogram}

Air bronchogram is defined as a pattern of air-filled (low density) bronchi on a background of opaque (high density) airless lung. Based upon the autopsy report, it is now clear that low attenuation is a gelatinous mucous, not air. Air bronchogram could be seen within ground opacity or consolidation. Air bronchogram is noticed in the asymptomatic and rapid progressive groups. There is great variability in the incidence of air bronchogram in COVID-19 patients ranging from 7 to $68.6 \%$ [17-21] (Figure 2).

\section{Air bubble sign}

Air bubble sign, also called round cystic changes. It describes a small air-containing space (low density) in the lung parenchyma. It could be attributed to pathological dilation of a physiological space or a cross-section of the bronchiectasis, or simply associated with the process of consolidation resorption, because infection causes damage to the alveolar walls and leads to pneumatoceles [22-28] (Figure 8).

\section{Subpleural curvilinear opacity}

Subpleural curvilinear lines are 1-3 $\mathrm{mm}$ in thickness, lying parallel to the pleural surface about $1 \mathrm{~cm}$ or less from the pleura. Subpleural linear opacity is seen up to $20.8 \%$ of COVID-19 patients, and this finding is not specific for COVID-19 [22-27].

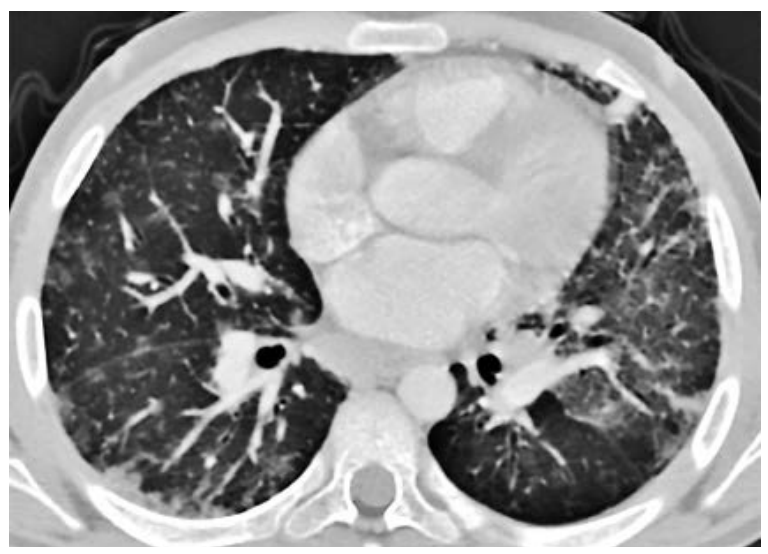

Figure 7. Centrilobular nodules. High-resolution computer tomography shows multiple centrilobular nodules at the right middle lung lobe. There are also a few small peripheral consolidations at the apical segment of the right lower lung lobe as well as the superior lingula, ground glass opacity at the superior lingula with thick interlobular septations, and right pleural thickening 


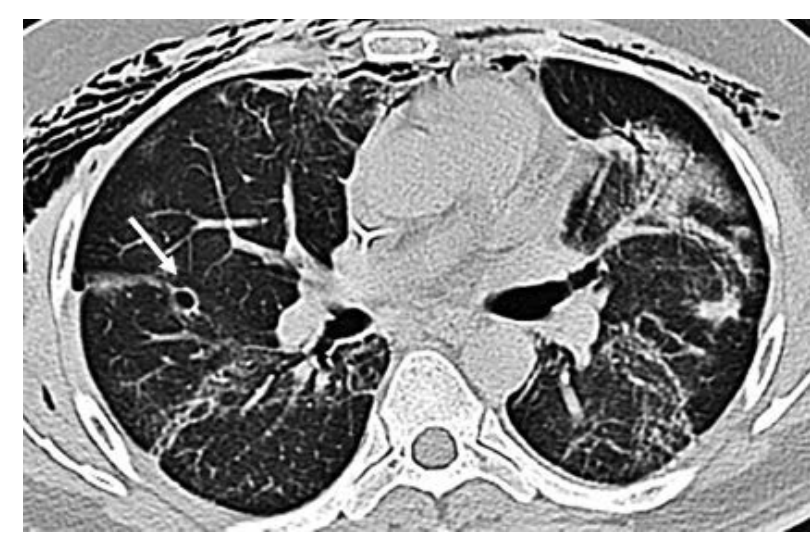

Figure 8. Air bubble sign. High-resolution computer tomography shows small air-containing spaces (white arrows) giving air bubble sign, together with bilateral peripheral ground glass opacity, small consolidation, air bronchogram, fibrotic bands, and subcutaneous surgical emphysema

\section{Reticulation pattern}

Reticulation pattern defined as a thickening of the interstitial structures like inter - and intra-lobular septations (stripe-like opacities). The formation of reticulations is associated with interstitial lymphocyte infiltration. It increases with the progress of the disease. The incidence of reticulation pattern in COVID-19 ranged from 50 to $80 \%$ [14-19] (Figure 9).

\section{Fibrosis}

Fibrosis defined as linear dense peripheral opacities, parenchymal bands, and irregular interfaces. Some authors consider traction bronchiectasis as part of fibrotic changes. It is seen more in severe cases and appears in the second week after the beginning of symptoms indicating interstitial disease. A recent study found that older patients with severe illness are more likely to develop fibrosis. However, the relation between fibrosis and prognosis of the disease is debatable because it is considered as a good prognostic sign with stabilising disease status by some researchers, while others suggest that fibrosis is a bad prognostic sign as patients progress to peak stage with further development of pulmonary interstitial fibrosis [23-31] (Figure 9).

\section{Extra-pulmonary findings}

\section{Bronchiectasis}

Bronchiectasis is defined as bronchial dilatation in comparison to the nearby pulmonary artery (signet ring sign), lack of tapering of bronchi, and identification of bronchi within $1 \mathrm{~cm}$ of the pleural surface. It is assumed that bronchiectasis occurs due to interstitial infiltration and fibrotic changes that occur later as the disease progresses. Bronchial deformity denotes irreversible damage, which may affect the respiratory function of the patient. The appearance of bronchiectasis is seen in the second week of

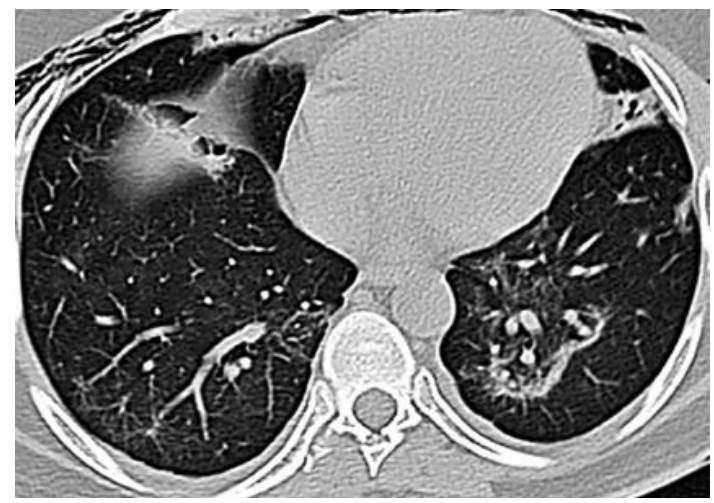

Figure 9. Reticulations and fibrosis. High-resolution computer tomography shows multiple bilateral reticulations (stripe sign) at posterior basal segment of the right lower lung lobe, fibrotic band at the posterior basal segment of the left lower lung lobe associated with small consolidation at the inferior lingua with air bronchogram

infection with COVID-19. Bronchial wall thickening may persist after healing and resolution of symptoms. Bronchial dilatation and traction bronchiectasis are reported in COVID-19 from 11 to 55\%. This variation could be explained by the fact that different studies assess patients at different stages of the disease, mostly during the initial mild form, while bronchiectasis is associated more with severe form [15-26] (Figure 10).

\section{Vascular enlargement in the lesion}

Vascular enlargement in the lesion is defined as the dilatation of pulmonary vessels within and/or around the lesions. Several researchers reported high incidences of vascular enlargement in COVID-19 ranging from 70 to $80 \%$, might have been caused by an acute inflammatory response with damage and swelling of the capillary wall. It should be differentiated from vascular changes seen with malignant infiltration by tumours such as bronchogenic adenocarcinoma, which is characterised by irregular vascular dilatation and vascular convergence [19-28] (Figure 11).

\section{Pulmonary embolism}

There is an increasing incidence of pulmonary embolism reported in patients suffering from COVID-19 (26-30\%). This was attributed either to prolonged stay in ICU with subsequent formation of deep vein thrombi or due to a hypercoagulability state because many cases had PE in their initial assessment [34,35] (Figure 12).

\section{Mediastinal lymphadenopathy}

Mediastinal lymphadenopathy is defined as enlarged mediastinal lymph nodes with short axis more than $10 \mathrm{~mm}$. It is described as a rare finding in COVID-19, is seen in a severe group. The associated mediastinal lymphadenopathy, pleural effusion, and nodules indicate secondary bacterial infection [36,37] (Figure 13). 


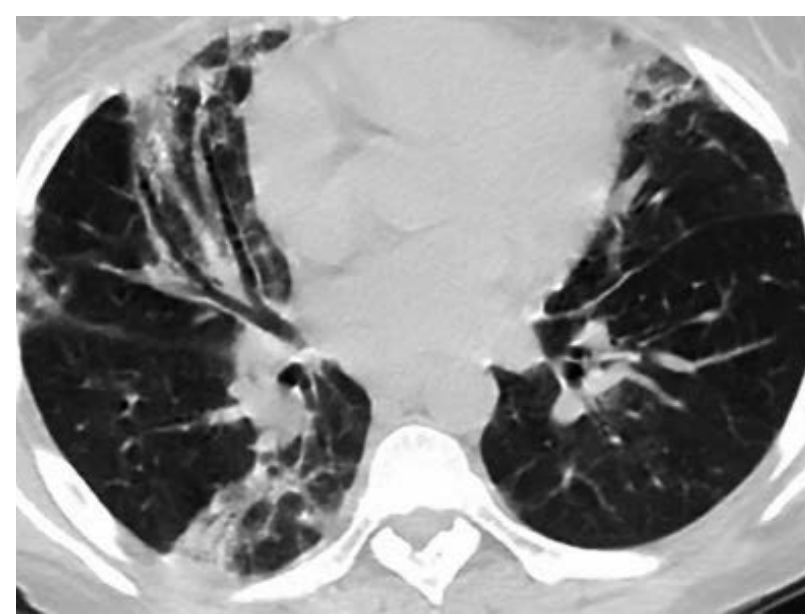

Figure 10. Bronchial changes. High-resolution computer tomography shows traction bronchiectasis with peri-bronchial thickening at a medial segment of the right middle lobe. It is associated with bilateral peripheral small consolidations

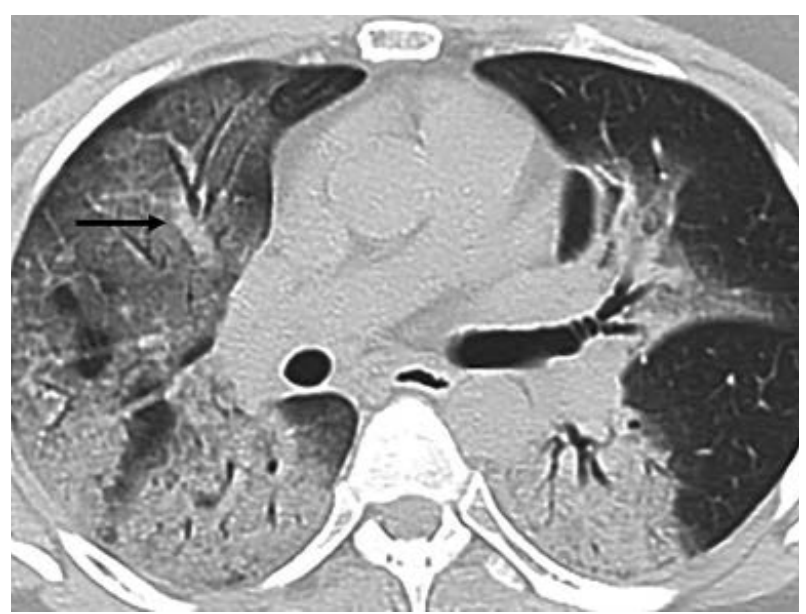

Figure 11. Vascular enlargement. High-resolution computer tomography shows enlarged pulmonary vein passing within ground glass opacity at the medial segment of the right middle lung lobe (vascular enlargement sign) black arrow. It is associated with consolidation at the apical segments of both lower ling lobes
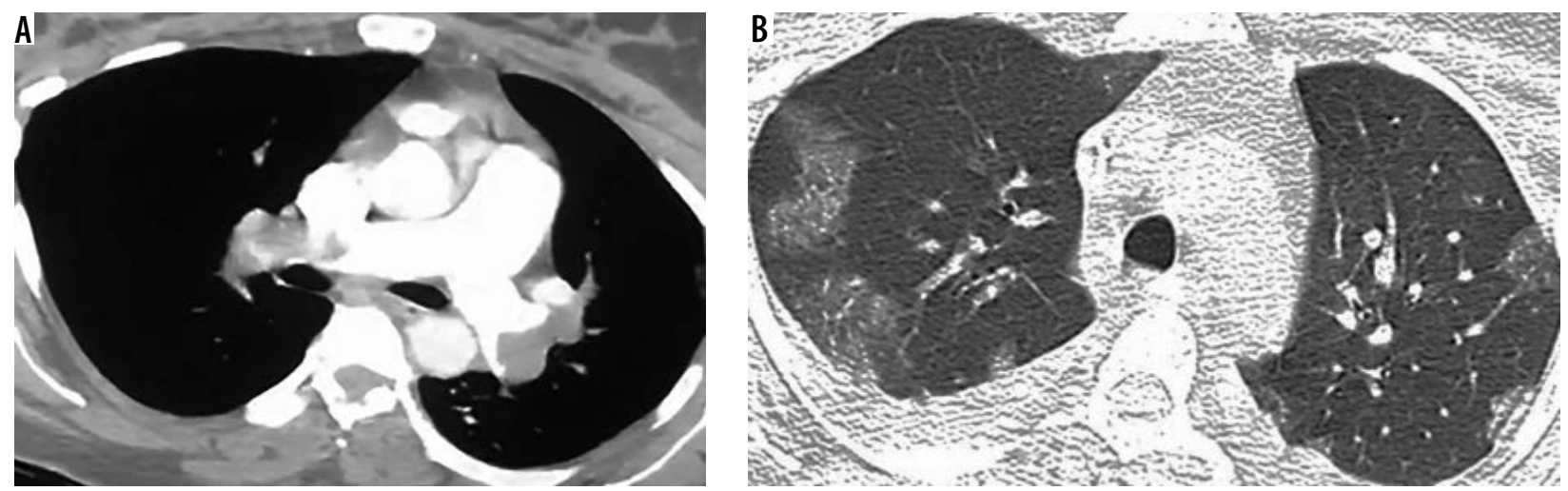

Figure 12. Pulmonary embolism. A) Computed tomography angiography pulmonary artery shows a hypodense filling defect in both pulmonary arteries (extensive pulmonary oedema). B) The same patients showed typical signs of COVID-19; high-resolution computer tomography shows bilateral multifocal subpleural ground glass opacity superimposed with thickened inter and intra-lobular septations (crazy paving) and bilateral pleural effusion, more on the right side

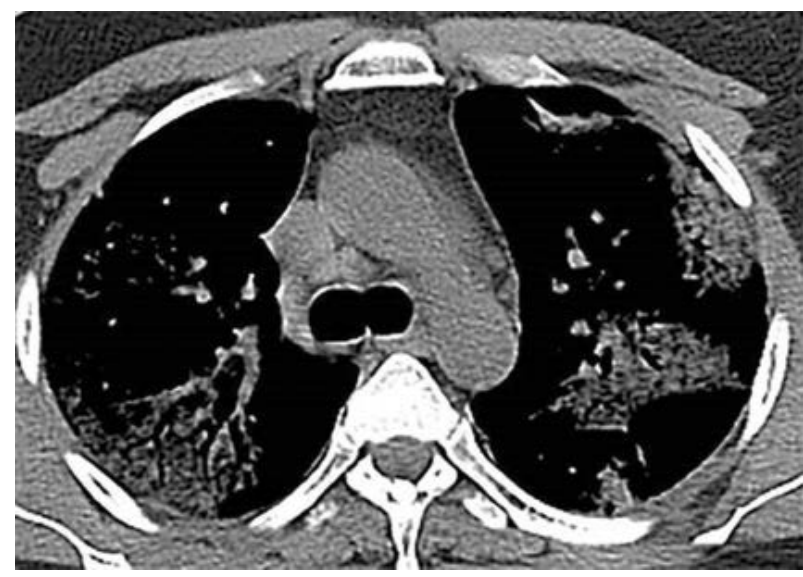

Figure 13. Mediastinal nodes. CT chest mediastinal window shows few enlarged middle mediastinal lymph nodes together with bilateral peripheral consolidations and air bronchogram

\section{Pleural thickening}

Pleural thickening either unilateral or bilateral is noted in about $32 \%$ of patients in the third week after the

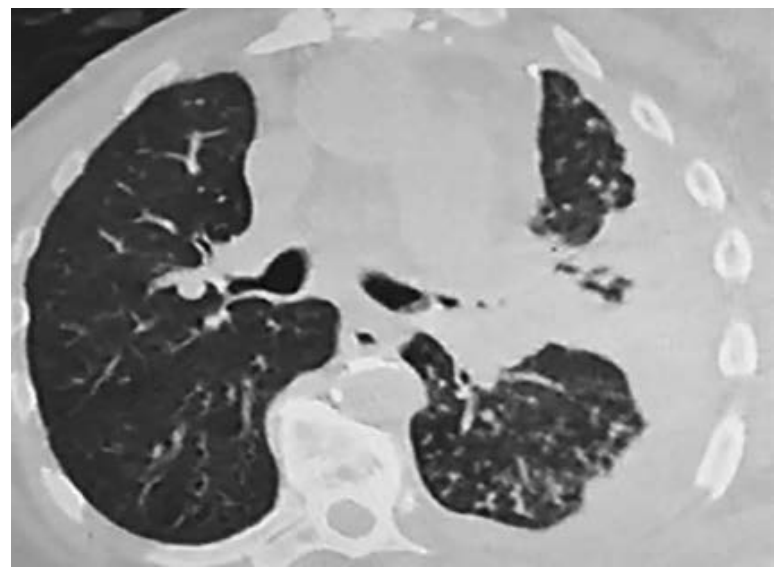

Figure 14. Pleural changes. High-resolution computer tomography shows left pleural effusion associated with consolidation of the superior lingula and centrilobular nodules at the apical segment of the left lower lung lobe

onset of infection. It is associated with a more aggressive form of the disease as it is associated with extensive adhesions in an autopsy. 


\section{Pleural effusion}

Pleural effusion several studies have reported an absence of pleural effusion in COVID-19 cases. Other researchers have reported the presence of pleural effusion in a minority of cases. Effusion is associated with a severe form of the disease that needs ICU admission or even ends with death. The occurrence of pleural effusion in patients with similar viral diseases such as MERS-CoV or avian influenza H5N1 is a poor prognostic sign [11-17] (Figure 14).

\section{Chest wall}

Surgical emphysema and pneumothorax are critical signs that are rarely described in COVID-19 patients, unlike other similar viral diseases (SARS). It is postulated that repeated cough and alveolar damage could be the cause. However, mechanical ventilation might be another causative factor [12-19] (Figure 15).

Finally, it is of great importance to highlight that normal CT of the chest does not exclude infection with COVID-19 as reported by many studies, especially in the first few days of infection [11-22].

\section{Paediatric chest computed tomography findings}

Chest CTs in children with COVID-19 infection show characteristic consolidation with surrounding halo sign due to underlying co-infection associated with increased calcitonin. These imaging findings are different from adults with COVID-19. Another difference is that children show generally milder form of lung affection with less multi-lobar involvement, less bilaterality, and rapid resolution $[38,39]$.

\section{Discussion}

\section{Classification and rational}

Different designs are proposed for structured reporting of COVID-19; all agree on the definition of typical radiological findings of typical COVID-19-related pneumonia and non-COVID-19-related pneumonia, but they have some differences regarding the definition of probable, atypical, or indeterminate features. The aim of structured reporting is to help radiologists to identify specific radiological features related to COVID-19, unify languages and terms, increase confidence in repots, and reach a better understanding of radiological reports by referring physicians.

An Italian group classified radiological signs of COVID-19 into three categories based on their experience with 702 patients. Category 1, which is negative for COVID-19, includes cases with no radiological signs suggestive of pneumonia or those who have signs specific for other types of pneumonia as viral and tuberculosis. About

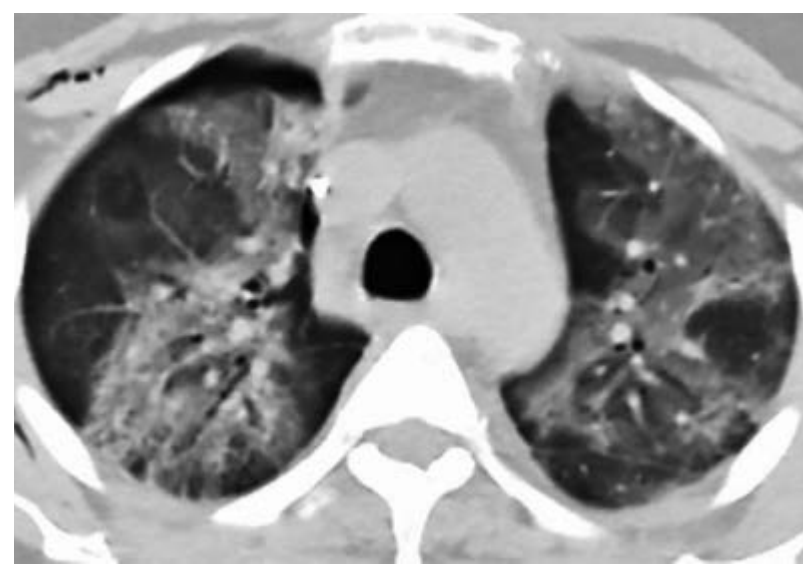

Figure 15. Surgical emphysema. High-resolution computer tomography shows small right pneumothorax, subcutaneous surgical emphysema, with bilateral multifocal peripheral ground glass opacity

$5 \%$ of patients who are negative for signs of pneumonia show typical signs of COVID-19 after one week. Category 2 is indeterminate for COVID-19, which includes cases showing radiological signs that could overlap or put as differential diagnosis with other types of pneumonia. Category 3 is typical COVID-19, which shows bilateral GGO/ consolidation in characteristic distribution. Categories 2 and 3 are further subdivided into mild and moderate/severe according to the severity [40] (Table 3).

British Society of Thoracic Imaging (BSTI) suggested another reporting system composed of four categories. Classic COVID-19 shows GGO \pm consolidation in characteristic distribution. Probable COVID-19 shows a lower lobe mix of bronchocentric and peripheral consolidations or scarce GGO. Indeterminate COVID-19 shows signs that do not fit into classic, probable, or non-COVID. Non-COVID (atypical) signs include lobar pneumonia, cavitation, centrilobular nodules, pleural effusion, lymphadenopathy, and established pulmonary fibrosis [41] (Table 4).

The Radiological Society of North America (RSNA) reporting system is the most commonly used and applied approach, they suggested four categories: typical (specific signs; GGO \pm consolidation in a characteristic distribution) (Figure 16); indeterminate (signs reported in COVID pneumonia but not specific enough, GGO lacking specific distribution, not rounded, and not peripheral) (Figure 17); atypical (signs uncommon with COVID-19 pneumonia but specific to other types of pneumonia, lobar consolidation, centrilobular nodules, cavitation, pleural effusion with reticulations); and negative for COVID pneumonia. It shares some similarities with the BSTI classification, but each has a different nomination for the same characters (atypical features in RSNA = non-COVID in BSTI). In addition, the RSNA classification provides a suggested reporting language in order to make it easier for clinicians to understand radiological terms. They mentioned that the decision to use the term COVID-19 in reports depends on several factors including suspicion for the infection, the prevalence of COVID-19, and institutional preferences, because describing a case as COVID or non- 
Table 3. Italian radiological signs determining the severity of COVID-19

\begin{tabular}{|c|c|c|}
\hline Radiology & Parenchymal lung changes & Severity \\
\hline \multicolumn{3}{|l|}{ Category 2, 3} \\
\hline & Up to 3 focal abnormalities, $3 \mathrm{~cm}$ in maximum diameter & Mild \\
\hline & More than 3 focal abnormalities or max diameter $>3 \mathrm{~cm}$ & Moderate/severe \\
\hline \multicolumn{3}{|l|}{ Category 3} \\
\hline Pure GGO & Up to 3 focal abnormalities, $3 \mathrm{~cm}$ in maximum diameter & Mild \\
\hline Pure GG0 & More than 3 focal abnormalities or max diameter $>3 \mathrm{~cm}$ & Moderate/severe \\
\hline Focal GG0 mixed with early consolidation & - & Moderate/severe \\
\hline $\begin{array}{l}\text { Diffuse } \mathrm{GGO} \text { or consolidation with signs } \\
\text { of architectural distortion }\end{array}$ & - & Severe \\
\hline
\end{tabular}

GG0 - ground glass opacity

Table 4. British Society Thoracic Imaging reporting of COVID-19

\begin{tabular}{|l|l|}
\hline Pattern & Description \\
\hline Classic COVID & Lower lobe predominant, peripheral predominant, multiple, bilateral* foci of GG0 \\
& $\begin{array}{l}\text { Crazy paving } \\
\text { Peripheral consolidation** }\end{array}$ \\
& $\begin{array}{l}\text { Air bronchogram } \\
\text { Reverse halo/peri-lobular pattern** }\end{array}$ \\
\hline $\begin{array}{l}\text { Probable COVID } \\
\text { (71-99\% confidence for COVID) }\end{array}$ & $\begin{array}{l}\text { Lower lobe mix of broncho-centric and peripheral consolidation } \\
\text { Reverse halo/perilobular pattern** }\end{array}$ \\
\hline $\begin{array}{l}\text { Indeterminate } \\
\text { (> 70\% confidence for COVID) }\end{array}$ & $\begin{array}{l}\text { Does not fit into classic, probable, or non-COVID } \\
\text { Manifests above patterns but the clinical context is wrong or suggests an alternative diagnosis } \\
\text { (interstitial lung disease in context of connective tissue disease setting) }\end{array}$ \\
\hline $\begin{array}{l}\text { Non-COVID, atypical } \\
\text { (70\% confidence for alternative) }\end{array}$ & $\begin{array}{l}\text { Lobar pneumonia } \\
\text { Cavitating infections } \\
\text { Tree in bud/centrilobular nodularity } \\
\text { Lymphadenopathy/effusions }\end{array}$ \\
\hline Established pulmonary fibrosis \\
\hline
\end{tabular}

${ }^{*}>1$ lesion, but could still be unilateral; usually but not universally bilateral, ${ }^{* *}$ i.e. organising pneumonia patterns

COVID would definitely narrow management options for the referring physicians [42] (Table 5).

The Dutch Radiological Society proposed a grading scale of the degree of suspicion of COVID-19 pneumonia ranging from low suspicion (Co-RAD 1) to high suspicion (Co-RAD 5) according to CT radiological findings. Co-RAD 0 is given if the image quality is insufficient for diagnosis. Co-RAD 1 means very low suspicion and is equivalent to non-COVID pneumonia in RSNA classification. Co-RAD 2 represents a low level of suspicion of COVID pneumonia; it is equivalent to atypical COVID in the RSNA classification. Co-RADS 3 is equivalent to indeterminate in the RSNA classification; it includes perihilar ground-glass, homogenous extensive GGO \pm sparing of some secondary pulmonary lobules, GGO with smooth inter-lobular septal thickening \pm pleural effusion, and small GGO that are not centrilobular and not lying near the visceral pleura. It also includes patterns of consolidation coping with organising pneumonia. Co-RAD 4 represents a high degree of suspicion with GGO that is either unilateral, in a peri-broncho-vascular distribution, or superimposed with pre-existing lung disease. It is equivalent to indeterminate in RSNA classification. Co-RAD 5 represents a very high degree of suspicion with GGO in peripheral bilateral multifocal distribution; it is equivalent to typical COVID pneumonia in RSNA classification. If the patient had positive RT-PCR at the time of examination, it is graded as Co-RAD 6. This scale is designed for regions with a high prevalence of COVID-19 infection. Co-RAD 1 has high negative predictive value (for patients complaining of $4 \mathrm{~d}$ or more), Co-RAD 5 has very high positive predictive value, while Co-RAD 2-4 shows variable predictive values and low interobserver agreement [43] (Table 6). 

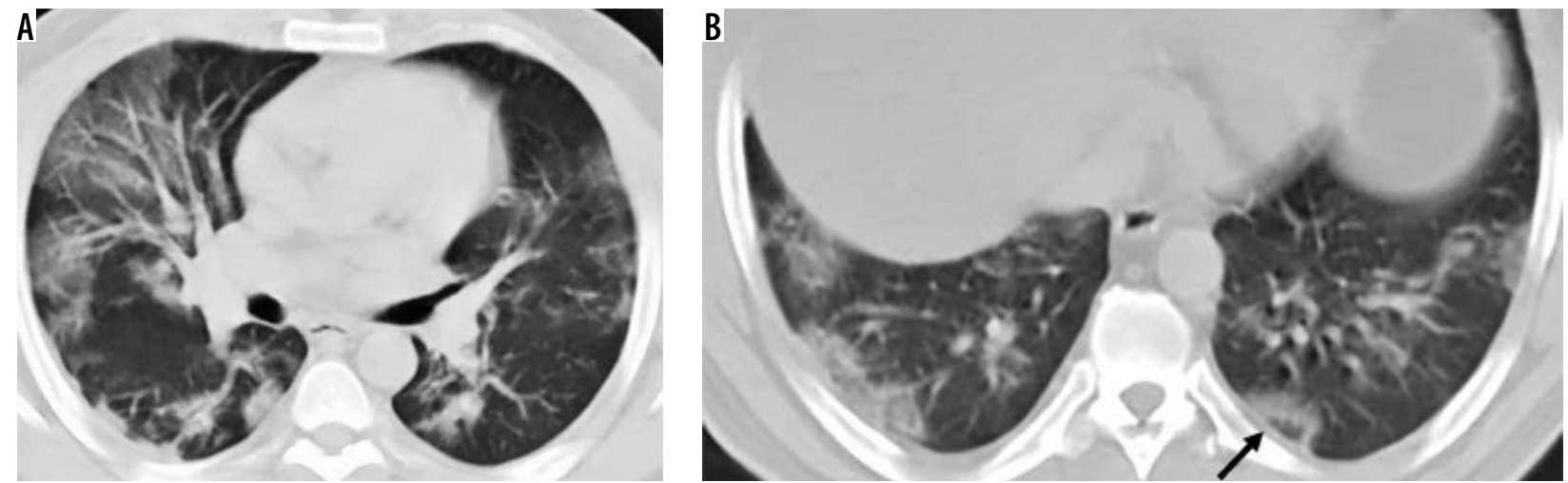

Figure 16. Classic COVID. A, B) Bilateral peripheral multifocal ground glass opacity + crazy paving + reversed halo sign (arrow) + peripheral consolidation (moderate form)
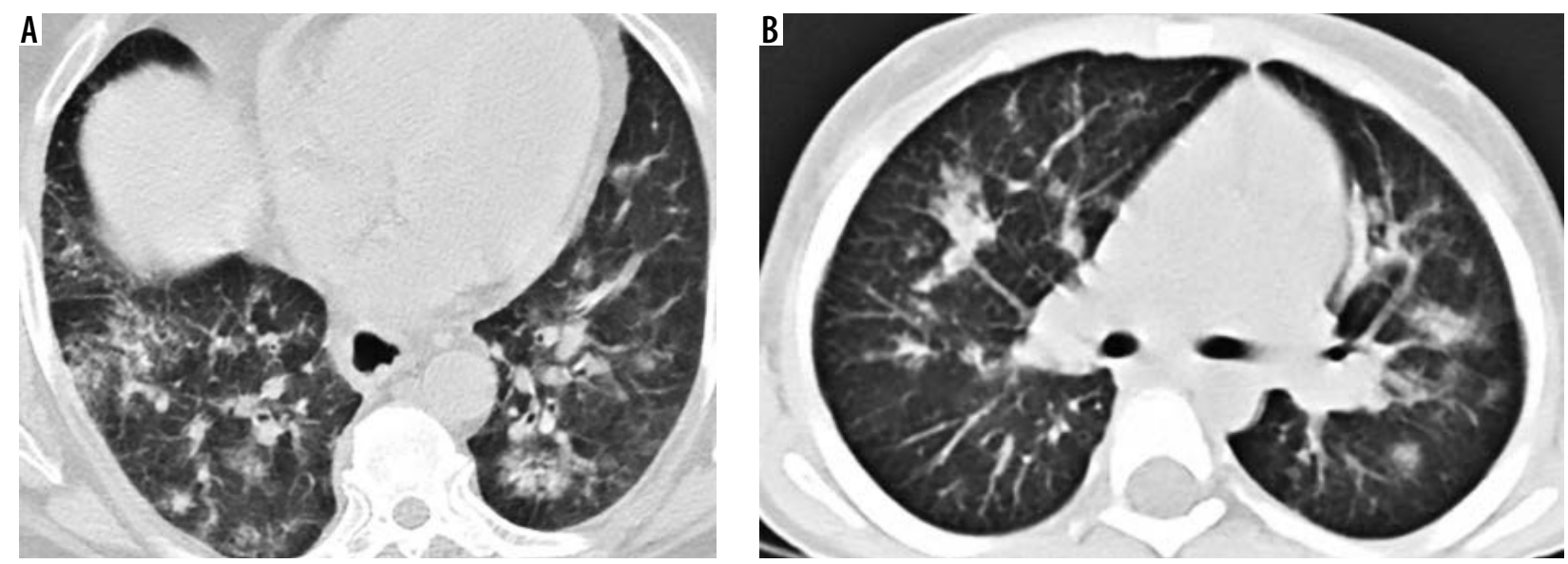

Figure 17. Indeterminate COVID. A) High-resolution computer tomography (HRCT) shows bilateral broncho-centric consolidation and reticular pattern (stripes), presence of reticulations suggests moderate form. B) Another patient HRCT shows bilateral peri-lobular and broncho-centric consolidations

Table 5. Structured reporting of COVID-19 according to RSNA and thoracic society

\begin{tabular}{|l|l|l|l|}
\hline $\begin{array}{l}\text { COVID-19 } \\
\text { pneumonia } \\
\text { imaging } \\
\text { presentation }\end{array}$ & Rationale & CT imaging findings & Suggested reporting language \\
\hline $\begin{array}{l}\text { Typical } \\
\text { appearance }\end{array}$ & $\begin{array}{l}\text { Commonly } \\
\text { reported imaging } \\
\text { features of } \\
\text { greater specificity } \\
\text { for COVID-19 } \\
\text { pneumonia }\end{array}$ & $\begin{array}{l}\text { Peripheral, bilateral, GG0 with or without consolidation or } \\
\text { visible intralobular lines ("crazy-paving") } \\
\text { Multifocal GGO of rounded morphology with or without } \\
\text { consolidation or visible intralobular lines ("crazy-paving") } \\
\text { Reverse halo sign or other findings of organising pneumonia } \\
\text { (seen later in the disease) }\end{array}$ & $\begin{array}{l}\text { Commonly reported imaging features of } \\
\text { (COVID-19) pneumonia are present. Other } \\
\text { processes such as influenza pneumonia and } \\
\text { organising pneumonia, and connective tissue } \\
\text { disease, can cause a similar imaging pattern }\end{array}$ \\
\hline $\begin{array}{l}\text { Indeterminate } \\
\text { appearance }\end{array}$ & $\begin{array}{l}\text { Nonspecific } \\
\text { imaging features } \\
\text { of COVID-19 } \\
\text { pneumonia }\end{array}$ & $\begin{array}{l}\text { Absence of typical features and presence of: } \\
\text { - Multifocal, diffuse, perihilar, or unilateral GGO with or } \\
\text { without consolidation lacking a specific distribution and } \\
\text { are non-rounded or non-peripheral scarce small GG0 in a } \\
\text { non-rounded and non-peripheral distribution }\end{array}$ & $\begin{array}{l}\text { Imaging features can be seen with (COVID-19) } \\
\text { pneumonia, though are nonspecific and can } \\
\text { occur with a variety of infectious and non- } \\
\text { infectious processes }\end{array}$ \\
\hline $\begin{array}{l}\text { Atypical } \\
\text { appearance }\end{array}$ & $\begin{array}{l}\text { Uncommonly } \\
\text { or not reported } \\
\text { features of } \\
\text { COVID-19 } \\
\text { pneumonia }\end{array}$ & $\begin{array}{l}\text { Absence of typical or indeterminate features and presence of: } \\
\text { - Isolated lobar or segmental consolidation without GG0 } \\
\text { - Discrete small nodules (centrilobular, "tree-in-bud") } \\
\text { - Lung cavitation } \\
\text { - Smooth interlobular septal thickening with pleural effusion }\end{array}$ & $\begin{array}{l}\text { Imaging features are atypical or uncommonly } \\
\text { reported for (COVID-19) pneumonia. Alternative } \\
\text { diagnoses should be considered }\end{array}$ \\
\hline $\begin{array}{l}\text { Negative for } \\
\text { pneumonia }\end{array}$ & $\begin{array}{l}\text { No features of } \\
\text { pneumonia }\end{array}$ & $\begin{array}{l}\text { No CT features of pneumonia } \\
\text { no CT findings present to indicate pneumonia } \\
\text { (note: (T may be negative in the early stages } \\
\text { of COVID-19) }\end{array}$ \\
\hline
\end{tabular}


Table 6. CO-RAD scale

\begin{tabular}{|l|l|l|}
\hline \multicolumn{3}{|c|}{ Level of suspicion of COVID infection } \\
\hline C0-RADS1 & No & $\begin{array}{l}\text { Normal or non-infectious } \\
\text { manifestations }\end{array}$ \\
\hline C0-RADS 2 & Low & $\begin{array}{l}\text { Abnormalities consistent of infections } \\
\text { other than COVID-19 }\end{array}$ \\
\hline C0-RADS3 & Indeterminate & Unclear whether COVID-19 is present \\
\hline C0-RADS 4 & High & Abnormalities suspicious for COVID-19 \\
\hline C0-RADS5 & Very high & Typical COVID-19 \\
\hline C0-RADS6 & PCR +ve & \\
\hline
\end{tabular}

\section{The role of chest computed tomography in COVID-19 management}

\section{Early detection in relation to a serological test}

The CT findings may be seen in patients with clinically suspicious but without positive RT-PCR; however, a normal CT scan of the chest is not considered exclusion of infection with COVID-19 [24-27]. The RT-PCR test for COVID-19 has high specificity and low sensitivity (60-70\%). The detection rate of the initial chest CT (98\%) is significantly higher $(p=0.001)$ than RT-PCR $(71 \%)$ in patients with COVID infection [46].

\section{Classification and staging}

Researchers have described the progress of the disease in patients with COVID-19 into four stages [8-13]. Earlystage $(0-4 d)$ - CT findings show focal GGC and/or consolidation $(40 \%)$, multifocal lung opacity $(40 \%)$ with peripheral predominance (50\%). Middle stage (5-13d) CT shows progressive disease with a crazy-paving pattern $(20 \%)$ and new or increasing consolidation with bilateral and multi-lobar involvement (85\%). Late-stage (14 $d$ or more) - CT shows varying degrees of clearing without complete resolution. A long-term sequel is fibrotic changes that include reticulations, inter-lobular septal thickening, and/or traction bronchiectasis $[47,48]$.

\section{Disease severity and guide to therapy}

CT scan of the chest can be used to assess the severity of involvement of the lungs by COVID-19 in order to guide patient management. Patients with severe form manifested by the presence of bilateral multiple lobular and subsegmental consolidation need to be admitted to the ICU, while patients with a mild form of the disease with bilateral GGO and subsegmental consolidation do not require ICU administration. Patients with severe form with diffuse heterogeneous consolidation with GGOs involving most of both lungs associated with bronchiectasis, presenting as "bilateral white lung", usually need a ventilator $[49,50]$.

\section{Surveillance with the response to therapy}

Patients are treated with antiviral, anti-inflammatory drugs, and antibiotic therapy. CT of the chest could be a valuable tool to assess disease regression in the form of a decrease in number and size of pulmonary consolidation or conversely to demonstrate disease progression with the appearance of crazy-paving and increase in size and number consolidation [14-19]. However, more studies are needed to determine the best time interval for followup and consensus from societies of chest and radiology for the protocol of management and surveillance of these patients [30-32].

\section{Prediction of secondary bacterial infection}

The presence of pleural effusion, multiple tiny lung nodules, and mediastinal lymphadenopathy are suggestive of overlying bacterial infection, which occurs in $15 \%$ of hospitalised patients. The presence of the overlying infection has a serious effect and necessitates the start of an aggressive course of antibiotics [13-19].

\section{Differentiation from simulating lesions}

Unfortunately, most of the CT findings of COVID-19 are non-specific and might overlap with other viral pneumonia like influenza, as well as other coronaviruses diseases such as SARS and MERS. The involvement of both lungs at the initial study is highly suggestive of COVID-19 compared to MERS and SARS, which are unilateral. In MERS (similar to COVID-19) the mean number of lung segments involved is higher in the mortality group than in the recovered group, and pleural effusion correlates with a poor prognosis. Some types of viral pneumonia (especially influenza pneumonia) show radiological features that may be identical to COVID-19. However, COVID-19 shows GGOs that are more peripheral than central and more reticular in pattern as well as vascular enlargement, less pleural effusion, and less lymphadenopathy. Heart failure could share similar features as COVID-19 but it shows GGOs of central and stepped distribution with more vascular enlargement sign and rapid improvement after effective treatment $[51,52]$.

\section{Screening with prevention and control}

Although most radiology societies do not recommend the use of chest $\mathrm{CT}$ as a routine screening for the detection of COVID-19 pneumonia, it can be used in certain occasions to screen patients with clinical signs suggestive of COVID-19 in order to take rapid measures such as early isolation and early treatment, and to control the outbreak using public health strategies. Hence, chest CT plays a role in the prevention and control of the disease. Radiologists better to prepare for a pandemic of COVID-19 all over the world [12-16]. 


\section{Other imaging modalities}

\section{Plain radiology}

Plain radiography shows GGGs that are mostly bilateral, peripheral, multifocal, and with lower lobe predominance, but it is less sensitive than CT (69\%). Consolidation, on the other hand, unlike $\mathrm{CT}$, is the most common radiological finding in X-ray of patients with COVID-19. Pleural effusion is found in a minority of cases (3\%) [53-55].

\section{Chest ultrasound}

Chest ultrasound shows various B-line patterns including bilateral focal, multifocal, or confluent thickening attributed to either interlobular septal thickening or hazy opacities that do not obscure the bronchial structures or lung parenchyma. Consolidations in a variety of patterns, including multifocal small, non-translobar, translobar with occasional mobile air bronchograms, thickening, and irregularity of subpleural lines, are reported in patients with COVID-19. The A-lines develop during the recovery phase $[56,57]$.

\section{Advanced computed tomography techniques}

Dual-energy CT improves the image quality with less radiation dose and motion artifacts [58]. Ultra-highresolution computer tomography shows a crazy-paving pattern and decreased lung volume [59]. Quantitative CT delineates the pulmonary distribution (GGO and consolidations) to assess the disease extension [60-62]. At positron emission tomography (PET) CT, lung lesions show high ${ }^{18} \mathrm{~F}-\mathrm{FDG}$ uptake with lymph node involvement.
Conversely, the disseminated disease is absent, a finding suggesting that COVID-19 has pulmonary tropism. Although ${ }^{18}$ F-FDG PET CT cannot be routinely used in an emergency setting, it can be applied in the differentiation of complex patients [63]. Artificial intelligence enables early detection of changes in the lung at CT and helps to reduce the turnaround time; this is essential for the mass population screening at the outbreak in China and all over the world because it decreases the workload of radiologists and clinicians and promotes rapid triaging $[64,65]$. Futures studies are needed with the application of routine and advanced MR imaging [66-74] for diagnosis and differentiation from other infective or granulomatous pulmonary lesions in the future.

\section{Conclusions}

We conclude that chest CT can detect pulmonary and extra-pulmonary findings of COVID-19. The typical CT features of COVID-19 infection are bilateral peripheral multifocal GGOs and/or lung consolidations, while the presence of extra-pulmonary findings denotes advanced disease. Different structured reporting systems have been developed to facilitate communication between the clinicians and radiologists. Lastly, CT plays a role in the initial diagnosis of disease progression and guidance of therapy, surveillance of patients with response to therapy, prediction of overlying bacterial infection, and differentiation from simulating lesions.

\section{Conflict of interest}

The authors report no conflict of interest.

\section{References}

1. Wu YC, Chen CS, Chan YJ. The outbreak of COVID-19: an overview. J Chin Med Assoc 2020; 83: 217-220.

2. Fu L, Wang B, Yuan T, et al. Clinical characteristics of coronavirus disease 2019 (COVID-19) in China: a systematic review and metaanalysis. J Infect 2020; 80: 656-665.

3. She J, Jiang J, Ye L, et al. 2019 novel coronavirus of pneumonia in Wuhan, China: emerging attack and management strategies. Clin Transl Med 2020; 9: 19.

4. Munster VJ, Koopmans M, van Doremalen N, et al. A novel coronavirus emerging in China - key questions for impact assessment. N Engl J Med 2020; 382: 692-694.

5. Li Q, Guan X, Wu P, et al. Early transmission dynamics in Wuhan, China, of novel coronavirus-infected pneumonia. N Engl J Med 2020; 382: 1199-1207.

6. Zhu N, Zhang D, Wang W, et al. A novel coronavirus from patients with pneumonia in China, 2019. N Engl J Med 2020; 382: $727-$ 733.
7. Young BE, Ong SWX, Kalimuddin S, et al. Epidemiologic features and clinical course of patients infected with SARS-CoV-2 in Singapore. JAMA 2020; 323: 1488-1494.

8. Wang C, Horby PW, Hayden FG, et al. A novel coronavirus outbreak of global health concern. Lancet 2020; 395: 470-473.

9. Lippi G, Plebani M. Laboratory abnormalities in patients with COVID2019 infection. Clin Chem Lab Med 2020; 58: 1131-1134.

10. Cucinotta D, Vanelli M. WHO declares COVID-19 a pandemic. Acta Biomed 2020; 91: 157-160.

11. Bao C, Liu X, Zhang H, et al. Coronavirus disease 2019 (COVID-19) CT findings: a systematic review and meta-analysis. J Am Coll Radiol 2020; 17: 701-709.

12. Zhu J, Zhong Z, Li H, et al. CT imaging features of 4121 patients with COVID-19: a meta-analysis. J Med Virol 2020; 92: 891-902.

13. Salehi S, Abedi A, Balakrishnan S, et al. Coronavirus Disease 2019 (COVID-19): a systematic review of imaging findings in 919 patients. AJR Am J Roentgenol 2020; 215: 87-93. 
14. Raptis CA, Hammer MM, Short RG, et al. Chest CT and coronavirus disease (COVID-19): a critical review of the literature to date. AJR Am J Roentgenol 2020; 215: 839-842.

15. Li Y, Xia L. Coronavirus disease 2019 (COVID-19): role of chest ct in diagnosis and management. AJR Am J Roentgenol 2020; 214 : 1280-1286.

16. Yang W, Sirajuddin A, Zhang X, et al. The role of imaging in 2019 novel coronavirus pneumonia (COVID-19). Eur Radiol 2020; 30: 4874-4882.

17. Duan YN, Zhu YQ, Tang LL, et al. CT features of novel coronavirus pneumonia (COVID-19) in children. Eur Radiol 2020; 30: 4427-4433.

18. Kang Z, Li X, Zhou S. Recommendation of low-dose CT in the detection and management of COVID-2019. Eur Radiol 2020; 30: 4356-4357.

19. Raptis CA, Hammer MM, Short RG, et al. Chest CT and coronavirus disease (COVID-19): a critical review of the literature to date. AJR Am J Roentgenol 2020; 215: 839-842.

20. Rubin GD, Ryerson CJ, Haramati LB, et al. The role of chest imaging in patient management during the COVID-19 pandemic: a multinational consensus statement from the fleischner society. Chest 2020; 158: 106-116.

21. Rubin GD, Ryerson CJ, Haramati LB, et al. The role of chest imaging in patient management during the COVID-19 pandemic: a multinational consensus statement from the fleischner society. Radiology 2020; 296: 172-180.

22. Bhat R, Hamid A, Kunin JR, et al. Chest imaging in patients hospitalized with COVID-19 infection - a case series. Curr Probl Diagn Radiol 2020; 49: 294-301.

23. Ye Z, Zhang Y, Wang Y, et al. Chest CT manifestations of new coronavirus disease 2019 (COVID-19): a pictorial review. Eur Radiol 2020; 30: 4381-4389.

24. Zhou Z, Guo D, Li C, et al. Coronavirus disease 2019: initial chest CT findings. Eur Radiol 2020; 30: 4398-4406.

25. Ye Z, Zhang Y, Wang Y, et al. Chest CT manifestations of new coronavirus disease 2019 (COVID-19): a pictorial review. Eur Radiol 2020; 30: 4381-4389.

26. Kim H. Outbreak of novel coronavirus (COVID-19): what is the role of radiologists? Eur Radiol 2020; 30: 3266-3267.

27. Yuan M, Yin W, Tao Z, et al. Association of radiologic findings with mortality of patients infected with 2019 novel coronavirus in Wuhan, China. PLoS One 2020;15: e0230548.

28. Razek AAKA, El Badrawy MK, Alnaghy E. Interstitial lung fibrosis imaging reporting and data system: what radiologist wants to know? J Comput Assist Tomogr 2020; 44: 656-666.

29. Lei DP, Fan B, Mao J, et al. The progression of computed tomographic (CT) images in patients with coronavirus disease (COVID-19) pneumonia: the CT progression of COVID-19 pneumonia. J Infect 2020; 80: e30-e31.

30. Guan CS, Lv ZB, Yan S, et al. Imaging features of coronavirus disease 2019 (COVID-19): evaluation on Thin-Section CT. Acad Radiol 2020; 27: 609-613.

31. Li M, Lei P, Zeng B, et al. Coronavirus disease (COVID-19): spectrum of CT findings and temporal progression of the disease. Acad Radiol 2020; 27: 603-608.

32. Mahajan A, Hirsch JA. Novel coronavirus: what neuroradiologists as citizens of the world need to know. AJNR Am J Neuroradiol 2020; 41: 552-554.
33. Sahu KK, Lal A, Mishra AK. An update on CT chest findings in coronavirus disease-19 (COVID-19). Heart Lung 2020; 49: 442-443

34. Grillet F, Behr J, Calame P, et al. Acute pulmonary embolism associated with COVID-19 pneumonia detected by pulmonary CT angiography. Radiology 2020; 296: E186-E188.

35. Danzi GB, Loffi M, Galeazzi G, et al. Acute pulmonary embolism and COVID-19 pneumonia: a random association? Eur Heart J 2020; 41: 1858 .

36. Zhou C, Gao C, Xie Y, et al. COVID-19 with spontaneous pneumomediastinum. Lancet Infect Dis 2020; 20: 510.

37. Sun R, Liu H, Wang X. Mediastinal emphysema, giant bulla, and pneumothorax developed during the course of COVID-19 pneumonia. Korean J Radiol 2020; 21: 541-544.

38. Xia W, Shao J, Guo Y, et al. Clinical and CT features in pediatric patients with COVID-19 infection: Different points from adults. Pediatr Pulmonol 2020; 55: 1169-1174.

39. Li W, Cui H, Li K, et al. Chest computed tomography in children with COVID-19 respiratory infection. Pediatr Radiol 2020; 50: 796799.

40. Sverzellati N, Milanese G, Milone F, et al. Integrated radiologic algorithm for COVID-19 pandemic. J Thorac Imaging 2020; 35: 228-233.

41. BSTI. Thoracic Imaging in COVID-19 Infection. Guidance for the Reporting Radiologist. British Society of Thoracic Imaging. Version 2. $16^{\text {th }}$ March 2020. Available from: https://www.bsti.org.uk/ media/resources/files/BSTI_COVID-19_Radiology_Guidance_version_2_16.03.20.pdf.

42. Simpson S, Kay FU, Abbara S, et al. Radiological Society of North America Expert consensus statement on reporting chest CT findings related to COVID-19. Endorsed by the Society of Thoracic Radiology, the American College of Radiology, and RSNA. J Thorac Imaging 2020; 35: 219-227.

43. Prokop M, van Everdingen W, van Rees Vellinga T, et al. CO-RADS - a categorical CT assessment scheme for patients with suspected COVID-19: definition and evaluation. Radiology 2020; 296 : E97-E104.

44. Fang Y, Zhang H, Xie J, et al. Sensitivity of chest CT for COVID-19: comparison to RT-PCR. Radiology 2020; 296: E115-E117.

45. Pan Y, Guan H, Zhou S, et al. Initial CT findings and temporal changes in patients with the novel coronavirus pneumonia (2019-nCoV): a study of 63 patients in Wuhan, China. Eur Radiol 2020; 30: 33063309.

46. Lin C, Ding Y, Xie B, et al. Asymptomatic novel coronavirus pneumonia patient outside Wuhan: the value of CT images in the course of the disease. Clin Imaging 2020; 63: 7-9.

47. Ai T, Yang Z, Hou H, et al. Correlation of chest CT and RT-PCR testing in coronavirus disease 2019 (COVID-19) in China: a report of 1014 cases. Radiology 2020; 296: E32-E40.

48. Xie X, Zhong Z, Zhao W, et al. Chest CT for typical 2019-nCoV pneumonia: relationship to negative RT-PCR testing. Radiology 2020; 296: E41-E45.

49. Shi H, Han X, Zheng C. Evolution of CT manifestations in a patient recovered from 2019 novel coronavirus (2019-nCoV) pneumonia in Wuhan, China. Radiology 2020; 295: 20.

50. Pan F, Ye T, Sun P, et al. Time course of lung changes on chest ct during recovery from 2019 novel coronavirus (COVID-19) pneumonia. Radiology 2020; 295: 715-721. 
51. Wang H, Wei R, Rao G, et al. Characteristic CT findings distinguishing 2019 novel coronavirus disease (COVID-19) from influenza pneumonia. Eur Radiol 2020; 30: 4910-4917.

52. Bai HX, Hsieh B, Xiong Z, et al. Performance of radiologists in differentiating COVID-19 from viral pneumonia on chest CT. Radiology 2020; 296: E46-E54.

53. Lomoro P, Verde F, Zerboni F, et al. COVID-19 pneumonia manifestations at the admission on chest ultrasound, radiographs, and CT: single-center study and comprehensive radiologic literature review. Eur J Radiol Open 2020; 7: 00231.

54. Jacobi A, Chung M, Bernheim A, Eber C. Portable chest X-ray in coronavirus disease-19 (COVID-19): a pictorial review. Clin Imaging 2020; 64: 35-42.

55. Wong HYF, Lam HYS, Fong AH, et al. Frequency and distribution of chest radiographic findings in COVID-19 positive patients. Radiology 2019; 296: E72-E78.

56. Soldati G, Smargiassi A, Inchingolo R, et al. Is there a role for lung ultrasound during the COVID-19 pandemic? J Ultrasound Med 2020; 39: 1459-1462.

57. Lu W, Zhang S, Chen B, et al. A clinical study of noninvasive assessment of lung lesions in patients with Coronavirus Disease-19 (COVID-19) by bedside ultrasound. Ultraschall Med 2020; 41: 300-307.

58. Agostini A, Floridi C, Borgheresi A, et al. Proposal of a low-dose, long-pitch, dual-source chest CT protocol on third-generation dual-source CT using a tin filter for spectral shaping at $100 \mathrm{kVp}$ for CoronaVirus Disease 2019 (COVID-19) patients: a feasibility study. Radiol Med 2020; 125: 365-373.

59. Iwasawa T, Sato M, Yamaya T, et al. Ultra-high-resolution computed tomography can demonstrate alveolar collapse in novel coronavirus (COVID-19) pneumonia. Jpn J Radiol 2020; 38: 394-398.

60. Colombi D, Bodini FC, Petrini M, et al. Well-aerated lung on admitting chest CT to predict adverse outcome in COVID-19 pneumonia. Radiology 2020; 296: E86-E96.

61. Shen C, Yu N, Cai S, et al. Quantitative computed tomography analysis for stratifying the severity of coronavirus disease 2019. J Pharm Anal 2020; 10: 123-129.

62. Tang L, Zhang X, Wang Y, et al. Severe COVID-19 pneumonia: assessing inflammation burden with Volume-rendered chest CT. Radiol Cardiothorac Imaging 2020; 2: e200044.

63. Zou S, Zhu X. FDG PET/CT of COVID-19. Radiology 2020; 296: E118.

64. Li L, Qin L, Xu Z, et al. Artificial intelligence distinguishes COVID-19 from community acquired pneumonia on chest CT. Radiology 2020; 296: E65-E71.

65. Hurt B, Kligerman S, Hsiao A. Deep learning localization of pneumonia: 2019 coronavirus (COVID-19) outbreak. J Thorac Imaging 2020; 35: W87-W89.

66. Razek A. Diffusion magnetic resonance imaging of chest tumors. Cancer Imaging 2012; 12: 452-463.

67. Razek A, Soliman N, Elashery R. Apparent diffusion coefficient values of mediastinal masses in children. Eur J Radiol 2012; 81: 1311-1314.

68. Razek A, Fathy A, Gawad TA. Correlation of apparent diffusion coefficient value with prognostic parameters of lung cancer. J Comput Assist Tomogr 2011; 35: 248-252.

69. Razek A, Elkammary S, Elmorsy AS, et al. Characterization of mediastinal lymphadenopathy with diffusion-weighted imaging. Magn Reson Imaging 2011; 29: 167-172.
70. Razek A, Gaballa G, Elashry R, et al. Diffusion-weighted MR imaging of mediastinal lymphadenopathy in children. Jpn J Radiol 2015; 33 : 449-454.

71. Razek A, Castillo M. Imaging appearance of granulomatous lesions of head and neck. Eur J Radiol 2010; 76: 52-60.

72. El-Serougy L, Razek A, Ezzat A, et al. Assessment of diffusion tensor imaging metrics in differentiating low-grade from high-grade gliomas. Neuroradiol J 2016; 29: 400-407.

73. Razek A, Gaballa G. Role of perfusion magnetic resonance imaging in cervical lymphadenopathy. J Comput Assist Tomogr 2011; 35: 21-25.

74. Surov A, Nagata S, Razek A, et al. Comparison of ADC values in different malignancies of the skeletal musculature: a multicentric analysis. Skeletal Radiol 2015; 44: 995-1000. 